\title{
Does the mitochondrial DNA play a role in the pathogenesis of diabetes?
}

\author{
K.-D. Gerbitz \\ Institutes of Clinical Chemistry and Diabetes Research, Krankenhaus München-Schwabing, Munich, FRG
}

Diabetes has, without doubt, a genetic background. However, despite extensive research worldwide we have until now been unable to define the genetic lesions and the mode of inheritance of the different forms of the disease. In Type 1 (insulin-dependent) diabetes mellitus the high discordance for the disease in genetically identical twins indicates that the nuclear genetic component per se is not sufficient for full penetrance. Furthermore, the rapidly rising incidence of Type 1 diabetes [1] cannot be explained on a mendelian genetic basis, as the enrichment of the gene pool with a putative "diabetes gene", for example, by increased survival of young diabetic patients, would require several hundred years for dominant and several thousand years for recessive inheritance [2]. The increasing incidence of the disease is therefore most likely due to changes in environmental exposures. Furthermore, the incidence of Type 1 diabetes is quite different among various populations. Definite reasons for these extraordinary geographic differences remain unknown. Type 2 (non-insulin dependent) diabetes exhibits several features of a degenerative disorder and can thus possibly be attributed to a variety of degenerative processes associated with defects in oxidative phosphorylation.

In the following I will discuss the possibility that environmental factors could preferentially affect the second human genome, the mitochondrial DNA, thus leading to metabolic, immunologic, genetic and phylogenetic alterations.

\section{The mitochondrial DNA}

Eukaryotic cells usually contain one nuclear genome and up to several thousand identical copies of the mitochondrial DNA (mtDNA). The sequence of the human mt genome, 16,569 base pairs (bp) in length, was published in 1981 [3]. Unlike the nuclear DNA, which is linear, the double-stranded mtDNA is circular and has a highly compacted structure consisting almost entirely of coding regions. It is almost exclusively maternally inherited, uses its own genetic code and codes for 13 subunits of the respiratory chain complexes, 22 transfer RNAs (tRNA) and 2 ribosomal RNAs (rRNA). Mitochondria have their own transcription and translation apparatus. Besides their nuclear genetic diversity, populations differ in mtDNA types ("alleles, clusters"). During the last decade restriction analysis and sequencing revealed an extreme polymorphism of point and length mutations within the mt genome [4]. Obviously, non-random branching patterns occurred during the 300,000 years of evolution resulting in different mtDNA lineages [5, 6], of which certain types seem relatively specific for one population.

\section{The mtDNA is vulnerable}

Although the mtDNA encodes highly conserved proteins it exhibits a very high mutation rate for the following reasons: The mt genome evolves 5-10 times faster than single copy nuclear DNA genes [7]. Its half-life is between 6-10 days in rat heart, liver and kidney compared to the nuclear DNA, which has a half-life of about 100 days in rat liver [7]. The mutability may also reflect the relatively high insertion error-rate of the mitochondrial DNA polymerase- $\gamma$ of about $1 / 7000$ bases, resulting in 2-3 mismatched nucleotides per round of replication of the 16.6 kilobases $(\mathrm{kb}) \mathrm{mt}$ genome [8]. Furthermore, the mtDNA is more exposed to chemical attack than the nuclear DNA because it is not protected by histones. Mitochondria reduce about $90 \%$ of the cell's oxygen; in man this equals about $2 \times 10^{20}$ molecules $\mathrm{O}_{2}$ per $\mathrm{g}$ of tissue per day [9]. Highly reactive oxygen species such as superoxide radicals, hydrogen peroxide and hydroxyl radicals are formed during aerobic metabolism along the mitochondrial respiratory chain. Even under normal conditions this oxidative stress leads to extensive damage especially of the mtDNA [10]. Since the mammalian mtDNA is highly organized and consists almost exclusively of coding regions, it is vulnerable. Thus, muta- 
tions could have functional significance. The lack of sufficient repair mechanisms of the $\mathrm{mt}$ genome confirms this view.

\section{Alterations of mtDNA are associated with disease}

During the last four years an increasing number of publications have shown that certain deletions, insertions or point mutations of the mtDNA are associated with distinct diseases (Fig.1). Large deletions or insertions are found in muscle mtDNA from patients with chronic progressive external ophthalmoplegia (CPEO) or the Kearns-Sayre syndrome (KSS) [11], in the brain of patients with Parkinson's disease, in dilatative and hypertrophic cardiomyopathy, in haemopoetic cells from patients with Pearson's marrow-pancreas syndrome and as a general result of ageing in tissues of apparently healthy elderly people [12]. Several point mutations were described in large pedigrees of the maternally inherited Leber's hereditary opticus neuropathy (LHON), in myoclonus epilepsy with ragged red fibres (MERRF), in myoencephalopathy with lactic acidosis and stroke-like episodes (MELAS), and in other clinically undefined disorders [12]. Most recently distinct point mutations of the mtDNA were also reported in brain sections from Alzheimer's patients [13] (Fig.1).

\section{The action of diabetogenic agents}

The action of various diabetogenic agents such as interleukin $1 \beta$ (IL-1 $\beta$ ), interferon $\gamma$, tumour necrosis factor $\alpha$, alloxan and streptozotocin (STZ) has been a subject of many excellent reviews during the last years. It is not the objective of this paper to repeat all the results contributed in this field. Briefly, there are at least two lines of operating mechanisms: $i)$ the formation of free radicals such as nitric oxide $\left(\mathrm{NO}^{\circ}\right)$ and the oxygen hydroxyl radical $\left({ }^{\circ} \mathrm{OH}\right)$; ii) alkylation of DNA and proteins (Fig.2). Formation of NO* occurs via L-arginine-dependent NO-synthase [14]. The mechanism, induced by IL-1 $\beta$, also operates in Beta cells, as recently demonstrated by electron paramagnetic resonance spectroscopy [15]. Prolonged exposure to IL$1 \beta$ of islets leads to a decrease of insulin secretion and an impairment of mitochondrial oxidation [16]. The mechanism is the liberation of iron from the iron-sulphur clusters within the catalytically active centres of the complexes I and II of the respiratory chain and the Krebs-cycle enzyme aconitase and the formation of iron-nitrosyl com-

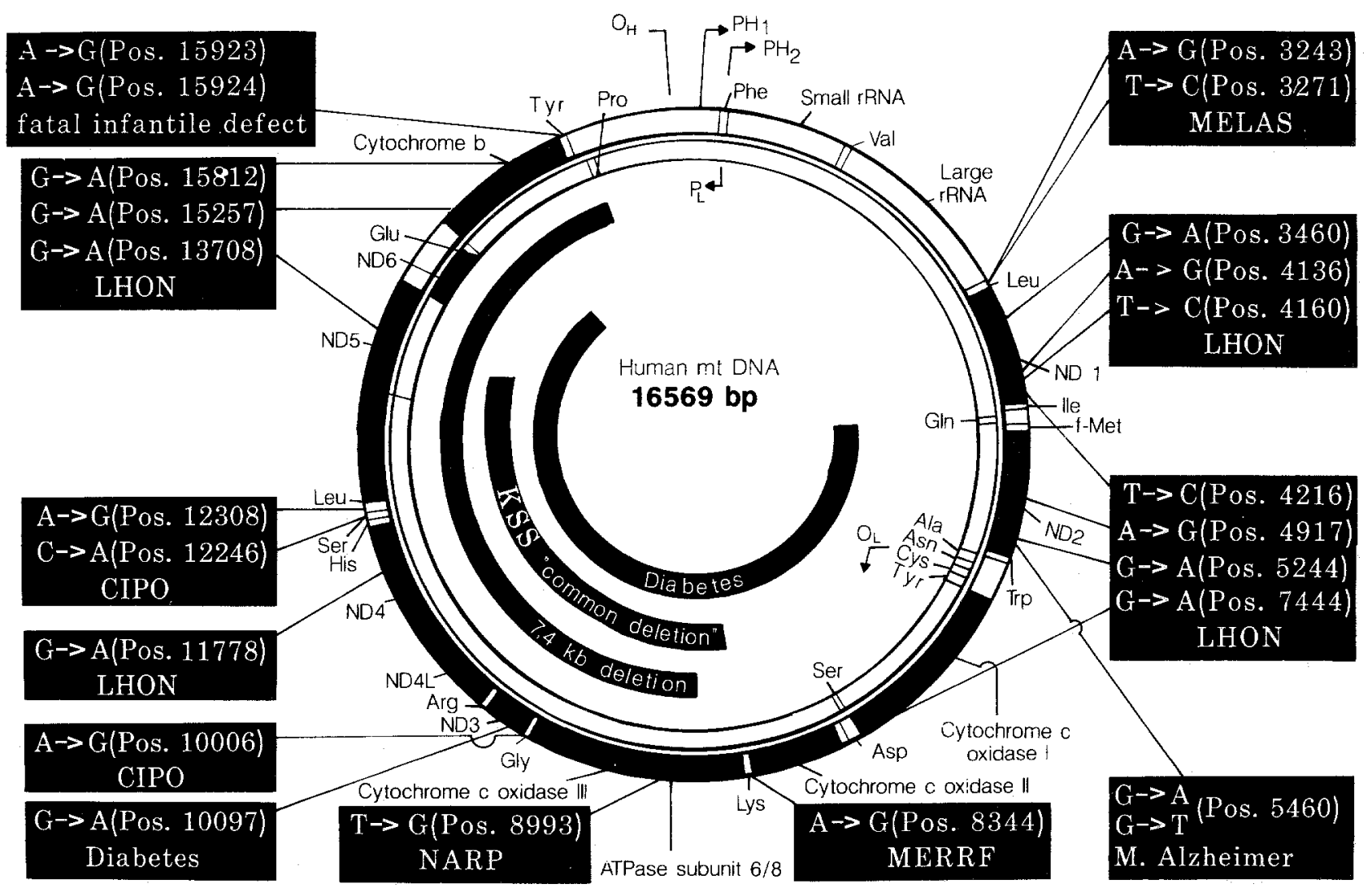

Fig. 1. Major disease mutations within the human mitochondrial (mt)DNA. Black regions indicate genes on the heavy (outer circle) and the light (inner circle) strand; transfer RNA (tRNA) genes are marked by solid lines with the respective amino acid abbreviations. $\mathrm{O}_{\mathrm{H}}, \mathrm{O}_{\mathrm{L}}, \mathrm{P}_{\mathrm{H}}, \mathrm{P}_{\mathrm{L}}$ are the respective origins of replication and the promoters for the heavy and light strands. Disease mutation base substitutions are shown outside the double stranded $\mathrm{mt}$ genome with the re- spective nucleotide positions. Regions removed by deletions are indicated by internal solid arcs. The $4977 \mathrm{bp}$ and the 7436 bp deletions are the most common, however several other deletions have been described [12]; the 10.4 kilobase $(\mathrm{kb})$ deletion is unique as it is found only in the diabetic family described in [47]. CIPO, chronic intestinal pseudoobstruction with myopathy and ophthalmoplegia; NARP, neurogenic muscle weakness, ataxia and retinitis pigmentosa 


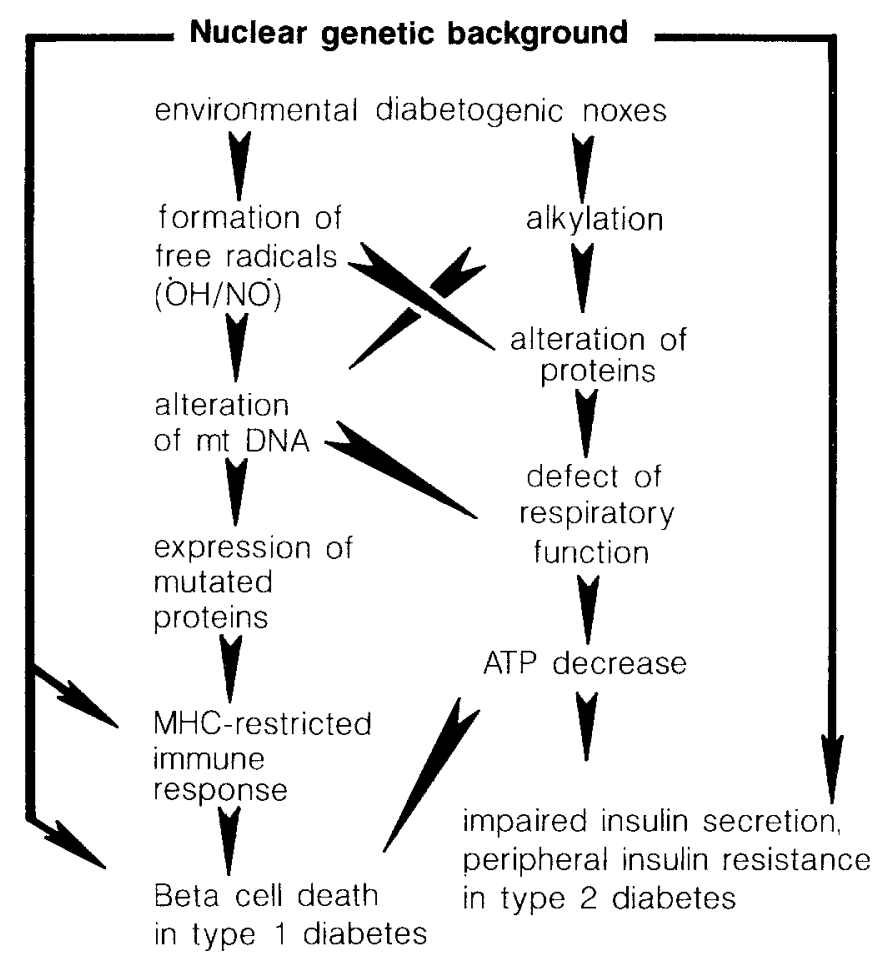

Fig. 2. Proposed mechanisms for the pathogenesis of diabetes

plexes $[15,17]$. $\mathrm{NO}^{\circ}$-generating compounds also inhibit DNA replication and stimulate $\mathrm{ADP}$-ribosyltransferase [14]. $\mathrm{NO}^{\circ}$, which is usually converted to $\mathrm{NO}_{2-}$ and $\mathrm{NO}_{3-}$ can undergo another pathway [18]. The simultaneous generation of nitric oxide and superoxide produces hydroxyl radicals via peroxynitrite. This could explain the partially protective effect of radical scavengers against IL$1 \beta$ with respect to damage of Beta cells. STZ and alloxan generate $\mathrm{H}_{2} \mathrm{O}_{2}$ in isolated islets and lead to DNA fragmentation $[19,20]$. Since superoxide and $\mathrm{H}_{2} \mathrm{O}_{2}$ do not per se undergo any chemical reactions with DNA the mechanism could either be the formation of ${ }^{\circ} \mathrm{OH}$ via reaction with metal ions or an acute rise in intracellular free $\mathrm{Ca}^{2+}$, which might fragment DNA by activating $\mathrm{Ca}^{2+}$-dependent endonucleases [21]. The hydroxyl radical ${ }^{\circ} \mathrm{OH}$ is extremely reactive attacking all components of the DNA. It can abstract hydrogen atoms from deoxyribose leading to direct release of purine and pyrimidine bases (abasic sites) or after incubation in alkaline solutions (alkali labile sites); it can add on to guanine and adenine, thus producing radical adducts with different fates [21]. The action of alloxan, but not STZ, can be prevented by addition of scavenger enzymes such as superoxide dismutase, catalase and glutathione reductase [22]. Inhibitors of the poly(ADP-ribose) synthetase, such as nicotinamide, benzamide etc., however, can prevent the development of diabetes induced by various diabetogenic agents in animal models [23] as well in humans [24]. These observations have led Okamoto [25] to hypothesise that all diabetogenic agents cause DNA strand breaks in islets resulting in the activation of the poly(ADP-ribose) synthetase mechanism, followed by NAD depletion and ultimately by death of Beta cells. Because STZ causes permanent defects in Beta cells independent of the NAD concentration, this hypothesis was recently questioned [26, 27].

\section{Evidence the mtDNA of Beta cells is preferentially attacked by diabetogenic agents in vitro and in vivo}

Beta cells are known to contain very small amounts of scavenger enzymes, especially of mitochondrial $\mathrm{Mn}$ superoxide dismutase $[22,28]$. The naked, i.e. non-histone-protected mtDNA resembles a mutation rate, which is $10-20$ fold higher than in the nuclear genome. For example, among the various oxidation products caused by radical attack, 8-hydroxy-2-deoxyguanosine is formed in mtDNA at 16 times the level of nuclear DNA after incubation with the prooxidant alloxan [10]. This compound might induce a $\mathrm{G}$. A mispair during replication leading to a G. C to $\mathrm{T} \cdot \mathrm{A}$ transformation mutation. The highly reactive hydroxyl radical ${ }^{\circ} \mathrm{OH}$ is also able to alter mitochondrial membrane lipids, a process which can be prevented by $\alpha$-tocopherol, but not by scavenger enzymes [29]. STZ suppresses the mRNA of mtDNA encoded cytochrome b, but has no effect on the transcript of the nuclear encoded glyceraldehyde-3-P-dehydrogenase in adult rat islets [30]. In islets isolated from STZ-treated neonatal rats it selectively depresses the mtDNA as compared to nuclear DNA, and consequently lowers mitochondrial gene expression [31].

Besides its ability to generate $\mathrm{H}_{2} \mathrm{O}_{2}$ and consequently hydroxyl radicals, STZ acts as an alkylating nitrosourea, which alkylates DNA at two main positions, the $\mathrm{N}^{7}$ - and the $\mathrm{O}^{6}$-position of guanine [26]. In the rat insulinoma cell line (RINr 38) STZ leads to the formation of alkali labile sites within the mtDNA [32]. The formation of methylated $\mathrm{N}^{7}$-guanine, which comprises about $70 \%$ of the alkylated adducts after exposure to STZ is about four-fold higher in the mtDNA compared to the nuclear DNA. This is consistent with former findings which have demonstrated, that the mtDNA is a preferential target of alkylating agents [33]. In the RINr 38 cell line repair of the $\mathrm{N}^{7}$ methylated sites seems to occur by an excision repair mechanism [32]. The efficiency of mitochondria in removing $\mathrm{O}^{6}$-alkylated sites varies between different cell types. It is high in parenchymal tissues such as the liver and lowest in "APUD" cells such as brain cells [34]. Sequencing of an approximately $200 \mathrm{bp}$ segment surrounding the replication origin of the $\mathrm{mtDNA}$ of STZ-treated islets did not, however, lead to sequencial differences when compared to the published mtDNA [31]. From this study it seems likely that STZ induces an all-or-nothing injury of the mtDNA. However, since islets exposed to STZ in vitro can survive for several weeks with basal oxygen consumption but reduced insulin release, STZ may also lead to partial mtDNA damage under certain conditions $[27,35]$.

\section{Are mutated mitochondrial gene products expressed and can they act as autoantigens?}

In KSS the so-called "common deletion", a 4,977 bp deletion flanked by a $13 \mathrm{bp}$ repeat (Fig. 1), produces a frame shift in the mt genome with three new triplets and a mito- 
chondrial stop codon $[36,37]$. This artificial fusion gene is transcribed, but the translation product could not be found [36]. Most recently, however, it was shown [38] that the introduction of disease-related mtDNA deletions into $\mathrm{HeLa}$ cells results in transcription and translation of the artificial hybrid genes, in dysfunction of the respectively affected respiratory chain complexes and ultimately in cell death. In mice and rats it was demonstrated that mitochondrially encoded peptides can serve as MHC-restricted antigens [39]. Mta, a maternally inherited murine minor histocompatibility antigen, is homologous to the mtDNA encoded ND1-subunit of complex I of the respiratory chain (NADH-ubiquinone oxidoreductase) and consists of four alleles differing in the amino acid composition at position 6 of the ND1-subunit [39]. Oligopeptides with different amino acids at this position can serve as antigens for the development of highly specific T-cell clones, when inserted into the plasma membrane of target cells. Since islets isolated from in vivo STZ-treated mice can induce a specific T-cell response in culture [40], STZinduced alterations on the surface of surviving Beta cells are likely. Although nothing is known about transport mechanisms of peptides from the mitochondrion to the endoplasmic reticulum and to the plasma membrane, the mouse and rat Mta-system prove that mitochondrially encoded self-peptides are normally displayed on the surface of cells [41]. Alterations of mtDNA encoded peptides could therefore contribute to the diversity of antigens. Keeping in mind the high mutability of the $\mathrm{mt}$ genome and the insufficient repair and scavenger mechanisms - especially in neuroendocrine cells - it seems reasonable that the mtDNA of Beta cells is one, if not the preferential target of diabetogenic noxae. A mutational event, once it occurred in a single mtDNA molecule, could provide an advantage for the mutated genome, for example by an enhanced replication of a shorter, i.e. deleted genome. If so, the number of mutated mtDNA molecules will increase. This may change the display of the mitochondrially encoded self-determinants on the surface of the Beta cells, resulting in a break of T-cell tolerance and in autoreactivity (Fig.2).

\section{Clinical evidence that the mtDNA may be involved in the pathogenesis of diabetes}

Patients with CPEO or KSS carrying large deletions of the $m t D N A$ have an incidence rate for diabetes which seems several times higher than in the general population. In a group of 21 patients presented by Quade et al. [42], three had Type 1 diabetes, two Type 2 diabetes and three impaired glucose tolerance. Association of mitochondrial encephalomyopathies with diabetes has already been mentioned by others $[43,44]$. Of the 27 patients with both diseases, mitochondrial myopathy and diabetes, reported in the literature so far, at least $50 \%$ are insulin-dependent. The earlier the onset of the mitochondrial myopathy the more frequent is its association with Type 1 diabetes [44]. Testing for islet cell antibodies was not performed, however, in any of the reported cases. Although no detailed studies have been published, single cases reported in the literature make it seem probable that also MELAS [45] and other mitochondrial cytopathies [46] are associated with diabetes. Since the mutation of the $\mathrm{mt}$ genome seems thus far to be the only genetic defect in these forms of disorders, the association of both diseases, mitochondrial myopathy and diabetes, makes it likely that alterations of the mtDNA of Beta cells to some degree contribute to the development of diabetes. Most recently [47] first direct evidence was given that alterations of the mtDNA can in fact cause diabetes. A systemic $10.4 \mathrm{~kb}$ mtDNA deletion was found in a family with maternally inherited insulindependent diabetes (Fig.1). Maternal transmission was also reported in a large family with Type 2 diabetes carrying a rare polymorphic mtDNA restriction site [48] (Fig. 1).

\section{Intergenomic interactions}

Replication and expression of the mtDNA depends on nuclear encoded proteins. Vice versa, the nucleus is a beneficiary of the energy currency within mitochondria [49]. Thus, alterations of the more vulnerable mtDNA might have dominant influences on the cross-talk between both genomes. For example, blocking the expression of mitochondrial gene products by ethidium bromide results in a failure for correct assembly and insertion into the inner mitochondrial membrane of most nuclear encoded respiratory chain subunits [50]. As noted recently by Avise [49], the exclusive maternal inheritance of the mtDNA can have negative influence on male fitness, a phenomenon demonstrated in a number of examples in the literature. With respect to Type 1 diabetes, several experimental observations could be related to this puzzling fact. Administration of STZ to rats and mice and the intake of the poison Vakor $[51,52]$ in man causes diabetes, mainly in males. Parental consumption of smoked/cured mutton, which is rich in N-nitroso compounds, leads to diabetes preferentially in the following male generation [53]. There are also several examples for protective maternal influence on penetrance and severity of a nuclear gene defect, for instance, in Huntington's disease and in myotonic dystrophy [54]. Also in Type 1 diabetes the prevalence is lower in children from affected mothers than fathers [55]. Since all children derive their mtDNA. from their mothers, co-transmission of maternal genes might represent a relatively protective factors. In general, the penetrance of a disease allele in a genetically programmed individual depends on its interaction with alleles of additional unlinked loci, on environmental agents and random factors [56]. If environmental noxae alter mtDNA this can become not only a catastrophic event for an individual, but could also initiate changes in population genetics on a relatively rapidly evolving level.

\section{The mitochondrial oxidative phosphorylation as a matrix for ageing and degenerative disorders}

Wallace has recently summarized [57] the basic concepts in the oxidative phosphorylation (OXPHOS) paradigm for degenerative diseases. Highly oxidative tissues such as 
brain, skeletal muscle, heart, kidney, liver and pancreatic islets depend on the capacity of the mitochondrial ATP generating system for their respectively specialized functions. Experimental inhibition of the respiratory chain and of oxidative phosphorylation results in an impairment of special tissue functions such as insulin production and secretion in Beta cells. The concept supposes that individuals normally start at the beginning of their lives with a high OXPHOS capacity. Due to defect accumulation of the mtDNA or of the nDNA or both, OXPHOS capacity declines with age. When the ATP production falls below a cell-specific energetic threshold the cell will be unable to function [38]. The maternally inherited mtDNA polymorphisms influence OXPHOS capacity, for example the maximal oxygen uptake and the response to endurance training [58]. Most of the random mutational events which underly the population specific mtDNA lineages seem to be neutral. However, this only means that they do not alter the functionality of OXPHOS capacity to a degree which reaches disease quality. In addition, even phenotypically silent mutations could slightly alter the functionality of the energy producing apparatus of the mitochondrion. The result could be either lower or higher susceptibility for a disease in an otherwise programmed individual, in affected families or even in populations.

\section{mtDNA phylogenetics and disease}

Encephalomyopathies such as MELAS, MERRF and LHON are characterized at the mtDNA level by distinct mutations, while some degenerative disorders such as Parkinson's disease, dilatative and hypertrophic cardiomyopathies are associated with deletions of the $\mathrm{mt}$ genome. Recently it has become evident that, in most cases, distinct mutations are not the only cause of a respective $\mathrm{mt}$ disease. By sequencing the $\mathrm{mt}$ genome of patients with Parkinson's disease, cardiomyopathy, MERRF or MELAS, Ozawa et al. [59] were able to demonstrate that these patients carry similar mtDNA clusters. From these clusters a phylogenetic tree was constructed, indicating that the patients, although suffering from phenotypically quite different disorders, belong to the same $\mathrm{mt}$ gene family. It also turned out that not a particular mutation, but the type and total number of mutations are indispensible factors for the disease. Similar results were published recently for the maternally inherited LHON demonstrating that the accumulation of synergistically interacting mutations of the $\mathrm{mt}$ genome, i. e. the degree of polymorphism, is responsible for the manifestation of a mitochondrial disease [60].

Since respective studies are lacking, one can only speculate whether population specific mtDNA lineages represent different possible targets for an environmental attack, thus possibly providing an explanation for the extraordinary geographic differences of the incidence rates of Type 1 diabetes.

Acknowledgements. I thank my colleagues Drs. E.Schleicher, B. Obermaier-Kusser and B. Olgemöller for their helpful discussion during preparation of the manuscript. Parts of our experimental work on mitochondrial myopathies underlying this article are supported by the Fritz Thyssen-Stiftung and the Wilhelm Sander-Stiftung.

\section{References}

1. Diabetes Epidemiology Research International Group (1990) Secular trends in incidence of childhood IDDM in 10 countries. Diabetes 39: 858-864

2. Murphy AE, Chase GA (1975) Principles of genetic counselling. Yearbook Medical Publishers, Chicago, pp 343-372

3. Anderson S, Bankler AT, Barek BG et al. (1981) Sequence and organization of the human mitochondrial genome. Nature 290: $457-465$

4. Cann RL, Stoneking M, Wilson AC (1987) Mitochondrial DNA and human evolution. Nature 325: 31-36

5. Hasegawa M, Horai S (1991) Time of the deepest root for polymorphism in human mitochondrial DNA. J Mol Evol 32: 37-42

6. Di Rienzo A, Wilson AC (1991) Branching pattern in the evolutionary tree for human mitochondrial DNA. Proc Natl Acad Sci USA 78: 5768-5772

7. Shay JW, Werbin H (1990) Cytoplasmic regulation of cellular differentiation: a role for mitochondria in carcinogenesis. In: Fisher PB (ed) Mechanisms of differentiation, vol I: model cell culture systems for studying differentiation. CRC Press, Inc., Boca Raton, pp 135-159

8. Kunkel TA, Loeb LA (1981) Fidelity of mammalian DNA polymerases. Science 213:765-768

9. Richter C (1988) Do mitochondrial DNA fragments promote cancer and aging? FEBS Lett 241:1-5

10. Richter C, Park JW, Ames BN (1988) Normal oxidative damage to mitochondrial and nuclear DNA is extensive. Proc Natl Acad Sci USA 85: 6465-6467

11. Holt IJ, Harding AE, Morgan-Hughes JA (1988) Deletions of muscles mitochondrial DNA in patients with mitochondrial myopathies. Nature 331: 717-719

12. Wallace DC, Lott MT, Torroni A, Shoffner JM (1991) Report of the committee on human mitochondrial DNA. Cytogenet Cell Genet 58: 1103-1123

13. Lin FH, Lin R, Wiesniewski HM et al. (1992) Detection of point mutations in codon 331 of mitochondrial NADH dehydrogenase subunit 2 in Alzheimer's brains. Biochem Biophys Res Comm $182: 238-246$

14. Moncada S, Palmer RMJ, Higgs EA (1991) Nitric oxide: physiology, pathophysiology and pharmacology. Pharmacol Rev 43: 109-142

15. Corbett JA, Lancaster JR, Sweetland MA, McDaniel ML (1991) Interleukin $1 \beta$-induced formation of EPR-detectable ironnitrosyl complexes in islets of Langerhans. Role of nitric oxide in interleukin-1 $\beta$-induced inhibition of insulin secretion. J Biol Chem 266: 21351-21354

16. Sandler S, Bendtzen K, Borg LAH, Eizirik DL, Strandell E, Welsh N (1989) Studies on the mechanism causing inhibition of insulin secretion in rat pancreatic islets exposed to human interleukin-1 $\beta$ indicate a perturbation in the mitochondrial function. Endocrinology 124: 1492-1501

17. Welsh N, Sandler S (1992) Interleukin-1 $\beta$ induces nitric oxide production and inhibits the activity of aconitase without decreasing glucose oxidation rates in isolated mouse pancreatic islets. Biochem Biophys Res Comm 182: 333-340

18. Hogg N, Durley-Usmar VM, Wilson MT, Moncada S (1992) Production of hydroxyl radicals from the simultaneous generation of superoxide and nitric oxide. Biochem J 281: 419-424

19. Uchigata Y, Yamamoto H, Kawamura H, Okamoto H (1982) Protection by superoxide dismutase inhibitors against alloxanand streptozotocin-induced islet DNA strand breaks. J Biol Chem 257:6084-6088

20. Wilson GL, Hartig PC, Patton NJ, Le Doux S (1988) Mechanisms of nitrosourea-induced $\beta$-cell damage. Diabetes 37:213-216 
21. Halliwell B, Aruoma OI (1991) DNA damage by oxygenderived species. Its mechanism and measurement in mammalian systems. FEBS Lett 281: 9-19

22. Malaisse WJ, Malaisse-Lagae F, Sener A, Pipeleers DG (1982) Determinants of selective toxicity of alloxan to the pancreatic $\beta$-cell. Proc Natl Acad Sci 79:927-930

23. Le Doux SP, Hall CR, Forbes PM, Patton NJ, Wilson GL (1988) Mechanisms of nicotinamide and thymidine protection from alloxan and streptozotocin toxicity. Diabetes 37: 1015-1019

24. Eliott RB, Chase HP (1991) Prevention or delay of type 1 (insulin-dependent) diabetes mellitus in children using nicotinamide. Diabetologia 34: 362-365

25. Okamoto $\mathrm{H}(1990)$ The molecular basis of experimental diabetes In: Okamoto $\mathrm{H}$ (ed) The molecular biology of the islets of Langerhans. Cambridge University Press, Cambridge, pp 209 231

26. Wilson GL, Leiter EH (1990) Streptozotocin interactions with pancreatic $\beta$-cell in the induction of insulin-dependent diabetes. Curr Topics Microbiol Immunol 156: 27-54

27. Eizirik DL, Sandler S, Ahnström G, Welsh M (1991) Exposure of pancreatic islets to different alkylating agents decreases mitochondrial DNA content but only streptozotocin induces longlasting functional impairment of B-cells. Biochem Pharmacol 42: 2275-2282

28. Asayama K, Kooy NW, Burr IM (1986) Effect of vitamin E deficiency and selenium deficiency on insulin secretory reserve and free radical scavenging systems in islets: decrease of islet mangano superoxide dismutase. J Lab Clin Med 107: 459-464

29. Hruskewycz AM (1988) Evidence for mitochondrial DNA damage by lipid peroxidation. Biochem Biophys Res Comm 153: 191-197

30. Svensson C, Welsh N, Krawetz S, Welsh M (1991) Exhibition of specific alterations in activities and $\mathrm{mRNA}$ levels of rat islet glycolytic and mitochondrial enzymes in three different in vitro model systems for attenuated insulin release. Diabetes 40: 771776

31. Welsh N, Pääbo S, Welsh M (1991) Decreased mitochondrial gene expression in isolated islets of rats injected neonatally with streptozotocin. Diabetologia 34: 626-631

32. Pettepher CC, Le Doux SP, Bohr VA, Wilson GL (1991) Repair of alkali-labile sites within the mitochondrial DNA of RINr 38 cells after exposure to the nitrosourea streptozotocin. J Biol Chem 266: 3113-3117

33. Wunderlich V, Schüt M, Böttger M, Graffi A (1970) Preferential alkylation of mitochondrial deoxyribonucleic acid by N-methylN-nitrosourea. Biochem J 118: 99-109

34. Satoh MS, Huh N, Rajewsky MF, Kuroki T (1988) Enzymatic removal of $\mathrm{O}^{6}$-ethylguanine from mitochondrial DNA in rat tissues exposed to $\mathrm{N}$-ethyl-N-nitrosourea in vivo. J Biol Chem 263: 6854-6856

35. Eizirik DL, Sandler S, Welsh N, Hellerström C (1988) Preferential reduction of insulin production in mouse pancreatic islets maintained in culture after streptozotocin exposure. Endocrino$\operatorname{logy}$ 122: 1242-1249

36. Mita S, Rizzuto R, Moraes CT et al. (1990) Recombination via flanking direct repeats is a major cause of large scale deletions of human mitochondrial DNA. Nucl Acid Res 18:561-567

37. Obermaier-Kusser B, Müller-Höcker J, Nelson I et al. (1990) Different copy number of apparently identically deleted mitochondrial DNA in tissues from a patient with Kearns-Sayre syndrome detected by PCR. Biochem Biophys Res Comm 169: $1007-1015$

38. Hayashi JI, Ohta S, Kikuchi A, Takemitsu M, Goto YI, Nonaka I (1991) Introduction of disease-related mitochondrial DNA deletions into HeLa cells lacking mitochondrial DNA results in mitochondrial dysfunction. Proc Natl Acad Sci USA 88: 10614 10618

39. Loveland B, Wang CR, Yonegawa H, Hermel E, Fischer-Lindahl K (1990) Maternally transmitted histocompatibility antigen of mice: a hydrophobic peptide of a mitochondrially encoded protein: Cell 60: 971-980
40. Klinkhammer C, Popowa P, Gleichmann H (1988) Specific immunity to streptozotocin. Cellular requirements for induction of lymphoproliferation. Diabetes 37: 74-80

41. Fischer-Lindahl K, Hermel E, Loveland BE, Wang CR (1991) Maternally transmitted antigen of mice: a model transplantation antigen. Annu Rev Immunol 9: 351-372

42. Quade A, Zierz S, Klingmüller D (1988) Endokrinologische Störungen bei Ophthalmoplegie plus/Kearns-Sayre Syndrom. Klin Wochenschr 66 [Suppl XIII]: 272-273

43. Lakin M, Locke S (1961) Progressive ocular myopathy with ovarian insufficiency and diabetes mellitus. Report of a case. Diabetes 10: 228-231

44. Tanabe Y, Migamoto S, Kinoshita Y et al. (1988) Diabetes mellitus in Kearns-Sayre syndrome. Eur Neur 28:34-38

45. Enter C, Müller-Höcker J, Zierz S et al. (1991) A specific point mutation in the mitochondrial genome of caucasians with MELAS: Hum Genet 88: 233-236

46. Rotig A, Bessis IL, Romero N et al. (1992) Maternally inherited duplication of the mitochondrial genome in a syndrome of proximal tubulopathy, diabetes mellitus and cerebellar ataxia. Amer J Hum Genetics 50: 364-370

47. Ballinger SW, Shoffner JM, Hedaya EV et al. (1992) Maternally transmitted diabetes and deafness associated with a $10.4 \mathrm{~kb}$ mitochondrial DNA deletion. Nature Genetics 1: 11-15

48. van den Ouweland JMW, Lemkes $H$, Maassen JA (1991) A rare mitochondrial BstNI polymorphism in a family with type 2 diabetes. Nucl Acid Res 19: 1962

49. Avise JC (1991) Ten unorthodox perspectives on evolution prompted by comparative population genetic findings on mitochondrial DNA. Annu Rev Genet 25: 45-69

50. Hayashi JI, Tanaka M, Sato W et al. (1990) Effects of ethidium bromide treatment of mouse cells on the expression and assembly of nuclear-encoded subunits of complexes involved in the oxidative phosphorylation. Biochem Biophys Res Comm 167:216221

51. Like AA, Rossini AA (1976) Streptozotocin-induced pancreatic insulitis: new model of diabetes mellitus. Science 193:415-417

52. Karam JH, Lewitt PA, Young CW et al. (1980) Insulinopenic diabetes after rodenticide (Vacor) ingestion. A unique model for acquired diabetes in man. Diabetes 29:971-978

53. Helgason T, Ewen SWB, Ross IS, Stowers JM (1982) Diabetes in mice produced by smoked/cured mutton. Lancet II: 1017-1024

54. Wallace DC (1987) Maternal genes: mitochondrial diseases. Birth Defects 23: 137-190

55. Warram JH, Krolewski AS, Gottlieb MS, Kahn CR (1984) Difference in risk of insulin-dependent diabetes in offspring of diabetic mothers and diabetic fathers. N Engl J Med 311: 149 152

56. Todd JA (1991) A prospective role of the environment in the development of type 1 diabetes. Diabetic Med 8: 906-910

57. Wallace DC (1992) Mitochondrial genetics: a paradigm for aging and degenerative diseases? Science 256: 628-632

58. Dionne FT, Turcotte L, Thibault C, Bouley MR, Skinner JS, Bouchard C (1991) Mitochondrial DNA sequence polymorphism $\mathrm{VO}_{2 \max }$, and response to endurance training. Med Sci Sports Exerc 23: 177-185

59. Ozawa T, Tanaka M, Sugiyama S et al. (1991) Patients with idiopathic cardiomyopathy belong to the same mitochondrial DNA gene family of Parkinsons's disease and mitochondrial encephalomyopathy. Biochem Biophys Res Comm 177: 518-525

60. Brown MD, Voljavec AS, Lott MT, Torroni A, Yang CC, Wallace DC (1992) Mitochondrial DNA complex I and III mutations associated with Leber's hereditary opticus neuropathy. Genetics 130: $163-173$

Dr. K.-D.Gerbitz

Institute für Klin. Chemie und Diabetesforschung

Krankenhaus Schwabing

KöIner Platz 1

W-8000 München 40

FRG 